\title{
INVESTIGAÇÃO DA CORROSÃO DE ARMADURA EM CONCRETOS COM DIFERENTES TIPOS DE AÇO ATRAVÉS DE ENSAIOS NÃO-DESTRUTIVOS
}

\author{
G. MODESTI \\ Mestrando, Engenheiro Civil \\ Universidade do Vale do Rio dos Sinos \\ Rio Grande do Sul, Brasil \\ gmodesti@avalisinos.com.br
}

\author{
M. MANCIO \\ Prof. Dr., Engenheiro Civil \\ Universidade do Vale do Rio dos Sinos \\ Rio Grande do Sul, Brasil \\ mancio@unisinos.br
}

\section{RESUMO}

O presente estudo tem como objetivo realizar o monitoramento de corpos-de-prova de concreto armado com aço CA50, CA-50 galvanizado e aço inoxidável austenítico 304, com e sem adição de $\mathrm{NaCl}$, através de diferentes ensaios não destrutivos, comparando os métodos entre si e os resultados qualitativa e quantitativamente. Observou-se que o ensaio de potencial de corrosão pode ser não conclusivo, como ocorrido em alguns aços galvanizados e inoxidáveis no concreto com $\mathrm{NaCl}$. Os ensaios de resistividade mostraram-se capazes de determinar os concretos mais suscetíveis a apresentar corrosão na armadura. Por fim, os ensaios de resistência de polarização, onde se obtém as densidades de corrente (Icorr), foram os mais indicativos da real situação das armaduras permitindo a avaliação quanto à passivação ou corrosão dos vergalhões e posterior conversão para taxas de corrosão, para a determinação de uma vida útil residual aproximada.

Palavras-chave: corrosão, RLP, potencial, resistividade, ensaios não-destrutivos.

\begin{abstract}
This paper focuses on the monitoring of concrete specimens reinforced with different types of steel (CA-50, galvanized and austenitic stainless steel) with and without $\mathrm{NaCl}$ added to the mix, through different non destructive testing methods, comparing the methods and the results qualitative and quantitatively. It was noticed that the corrosion potential may not be conclusive as has happened with some of the galvanized and stainless steels on the concretes with $\mathrm{NaCl}$ added to the mix. The resistivity tests were able to determine the situations more susceptible to have rebar corrosion. Lastly, the linear polarization resistance tests, where the corrosion density (Icorr) is obtained, were the most indicative of the real rebar situation, making it possible the evaluation of the passivation or corrosion of the rebars and then the conversion to corrosion rate to determine an approximate residual life.
\end{abstract}

Keywords: corrosion, LRP, potential, resistivity, non-destructive testing

\section{INTRODUÇ̃̃̃O}

Estruturas de concreto armado, antes pensadas como perpétuas, vêm se mostrando, em vários casos, extremamente suscetíveis à ação de agentes agressivos que provocam a degradação das mesmas com o surgimento de diversas manifestações patológicas (MEHTA, MONTEIRO, 2014). Estudos indicam que a principal causa de manifestações patológicas nestas estruturas é a corrosão e esta provoca, anualmente, custos elevados de manutenção e recuperação (GONZALEZ et al, 2004; ELSENER, 2005; BROOMFIELD, 2008).

Além dos gastos excessivos, a corrosão gera também a diminuição da durabilidade e vida útil das estruturas. As estruturas em concreto armado atuais apresentam manifestações patológicas de corrosão com uma frequência muito maior do que há 40 anos. Isso se dá pelo fato de que estas vêm sendo dimensionadas de maneira mais esbelta e executadas com concretos com maiores relações água/cimento, o que pode levar a uma diminuição de sua vida útil (KULAKOWSKI, 2002, MICHEL et al, 2016). Agravando a situação, com o crescimento dos centros urbanos, da industrialização, da poluição bem como a presença do ambiente marítimo na costa brasileira, criam-se ambientes favoráveis à corrosão (CASCUDO, 1997).

As leis da termodinâmica determinam que todos elementos têm tendência à buscar seu estado energético de equilíbrio com o meio ambiente em que se encontram. Isso se dá pela redução da energia livre que possuem (CARINO, 1999). No caso específico do aço, muita energia é empregada na sua produção, para extração, remoção de impurezas e 
conformação. Desta maneira, este produto se torna metaestável com tendência a retornar ao seu nível energético mais baixo, como encontrado na natureza (óxidos de ferro) através de reações com oxigênio e água, formando a corrosão (CARINO, 1999; DAVIS, 2000, PANNONI, 2007, LIU et al, 2016).

Os diferentes processos que levam à despassivação e, consequentemente, à corrosão, como a carbonatação e a ação de íons cloretos, entre outros, se distinguem nas características da manifestação patológica apresentada. A penetração dos íons cloreto despassivam a armadura localizadamente, dando origem a pequenas zonas anódicas, envoltas por grandes zonas catódicas ainda passivadas (HANSSON, 1984). Como as reações em ambas as células ocorrem na mesma velocidade e suas áreas são muito diferentes, há uma concentração de corrosão em um pequeno local, dando origem a pites e perdas de seção elevadas, localizadamente.

A perda de seção máxima nos pites pode ser de 4 à 8 vezes maior do que à estimada em uma corrosão generalizada (como na carbonatação) através da perda de massa (FIGUEIREDO et al, 2011), sendo que as densidades de corrente no fundo destas cavidades podem chegar a $20 \mu \mathrm{A} / \mathrm{cm}^{2}$ (BROOMFIELD, 2006).

A utilização de monitoramento de estruturas permite a avaliação da segurança das estruturas e diminuição de gastos relacionados à sua manutenção. No caso específico da corrosão, sensores portáteis ou embutidos na estrutura permitem o controle de diversas características da estrutura, como $\mathrm{pH}$, umidade, potencial eletroquímico, resistividade do concreto, resistência de polarização, fluxo de oxigênio, etc (FIGUEIREDO et al, 2011). Neste sentido, a RILEM lançou recomendações para a utilização das técnicas de resistividade do concreto, potencial de corrosão e resistência de polarização, respectivamente, em situações de campo (RILEM, 2000; RILEM, 2003; RILEM 2004).

A realização de ensaios de potencial de corrosão, bem como mapas apontando locais deteriorados, é a base para inspeções mais detalhadas, enquanto que ensaios de resistividade do concreto permitem a determinação da umidade presente no concreto, apresentando uma relação direta com taxas de corrosão. Ainda, conforme previsto na ASTM C876 seus valores absolutos permitem definir a probabilidade de corrosão de uma determinada amostra. Já Broomfield (2008) afirma que medidas de taxas de corrosão é a maneira mais eficaz possível, com a tecnologia atual, de determinar o real estado de degradação de uma estrutura, conforme Tabela 1.

Tabela 1: Valores de Icorr e Vcorr para avaliação de corrosão

\begin{tabular}{c|c|c}
\hline Icorr $\left(\mu \mathrm{A} / \mathrm{cm}^{2}\right)$ & Vcorr $(\mathrm{mm} / \mathrm{ano})$ & Nível de corrosão \\
\hline$\leq 0,1$ & $\leq 0,001$ & Negligível \\
\hline $0,1-0,5$ & $0,001-0,005$ & Baixo \\
\hline $0,5-1,0$ & $0,005-0,010$ & Moderado \\
\hline$>1,0$ & $>0,010$ & Alto \\
\hline
\end{tabular}

Fonte: RILEM (2004, p.635). Traduzido pelos autores.

A RILEM (2000) apresenta valores usuais de resistividade para concretos com e sem adições (Tabela 2). Já Broomfield (2006) e a RILEM (2000) propõem os valores demonstrados na Tabela 3 para correlação com a intensidade da corrosão a serem utilizados de referência para relação da resistividade com o risco de corrosão. 
Tabela 2: Referência de valores de resistividade para concretos de cimento Portland com e sem adições.

\begin{tabular}{c|c|c}
\hline \multirow{2}{*}{ Ambiente } & \multicolumn{2}{|c}{ Resistividade do concreto $(\Omega . m)$} \\
\cline { 2 - 3 } & $\begin{array}{c}\text { Cimento Portland } \\
\text { sem adições }\end{array}$ & $\begin{array}{c}\text { Adição de escória de alto-forno }(>65 \%) \text { ou cinza } \\
\text { volante }(>25 \%) \text { ou sílica ativa }(>5 \%)\end{array}$ \\
\hline $\begin{array}{c}\text { Muito úmido, submerso, zona de } \\
\text { respingo, sala de cura }\end{array}$ & $50-200$ & $300-1000$ \\
\hline $\begin{array}{c}\text { Externo, exposto } \\
\text { Externo, abrigado, revestido, } \\
\text { hidrofobizado }\left(20^{\circ} \mathrm{C} / \text { UR 80\%), }\right. \\
\text { não carbonatado }\end{array}$ & $200-500$ & $500-2000$ \\
\hline $\begin{array}{c}\text { Externo, abrigado, revestido, } \\
\text { hidrofobizado }\left(20^{\circ} \mathrm{C} / \mathrm{UR} 80 \%\right), \\
\text { carbonatado }\end{array}$ & $\geq 1000$ & $2000-6000$ ou mais \\
\hline $\begin{array}{c}\text { Interno, carbonatado }\left(20^{\circ} \mathrm{C} / \mathrm{UR}\right. \\
50 \%)\end{array}$ & $\geq 3000$ & $4000-10000$ ou mais \\
\hline
\end{tabular}

Fonte: RILEM (2000, p. 609). Traduzido pelo autor

Tabela 3: Interpretação das resistividades conforme Broomfield (2006) e RILEM (2003)

\begin{tabular}{c|c|c}
\hline $\begin{array}{c}\text { Resistividade } \\
(\Omega . \mathrm{m})\end{array}$ & Indicação (Broomfield, 2006) & $\begin{array}{c}\text { Risco de corrosão } \\
(\text { RILEM, 2003) }\end{array}$ \\
\hline$>1000$ & Não é possível distinguir aço despassivado de passivado & Negligível \\
\hline $500-1000$ & Taxa de corrosão baixa & Baixo \\
\hline $100-500$ & Taxa de corrosão moderada à alta onde o aço está despassivado & Moderado \\
\hline$<100$ & A resistividade não controla a taxa de corrosão & Alto \\
\hline
\end{tabular}

Fonte: Broomfield (2006, p. 68) e RILEM (2000, p. 610). Traduzido e adaptado pelo autor

O presente trabalho tem como objetivo verificar o comportamento de aços de baixo teor de carbono (CA-50), galvanizados e inoxidáveis em concretos com diferente relação a/c e teores de cloretos, através de ensaios eletroquímicos.

\section{MATERIAIS E PROGRAMA EXPERIMENTAL}

Realizou-se o monitoramento e análise da evolução dos parâmetros de potencial de corrosão (Ecorr), resistividade do concreto $(\rho)$ e de densidade de corrente (Icorr) em peças de concreto armado com e sem adição de cloreto de sódio $(\mathrm{NaCl})$ e aços do tipo CA-50, CA-50 galvanizado e inoxidável austenítico 304, Ø12,5 mm. O monitoramento foi realizado através de ensaios pontuais, nas idades de 14, 21, 28, 35, 50, 70 e 90 dias de idade, com o equipamento GECOR 8. Para os ensaios, moldaram-se oito corpos-de-prova, sendo duas amostras para cada situação avaliada. Os corpos-de-prova possuíam dimensões de 80x30x10 cm, com vergalhões espaçados entre si por $20 \mathrm{~cm}$. Em cada corpo de prova, colocaram-se uma amostra de cada tipo de aço ensaiado. $\mathrm{O}$ cobrimento utilizado foi de $2,5 \mathrm{~cm}$, representativo da classe de agressividade ambiental II da ABNT NBR 6118:2014. Utilizou-se cimento CP V-ARI, areia quartzosa de granulometria fina e brita basáltica.

Adicionou-se uma quantidade de $3 \%$ de $\mathrm{NaCl}$ em relação à massa de cimento de cada traço. Este procedimento foi realizado para proporcionar a corrosão ativa sem a necessidade de indução de corrente externa. Os concretos com relação a/c 0,45 foram confeccionados com traço unitário 1: 1,50: 2,04, consumo de cimento de $486 \mathrm{~kg} / \mathrm{m}^{3} \mathrm{e} \mathrm{teor} \mathrm{de}$ argamassa de 55\%. O abatimento verificado para o traço sem adição de $\mathrm{NaCl}$ foi de $130 \mathrm{~mm}$ e para o com adição de $\mathrm{NaCl} 125 \mathrm{~mm}$. Já para os concretos com relação a/c 0,65, utilizou-se traço unitário 1: 2,40: 2,78, também com teor de argamassa de $55 \%$ e consumo de cimento de $350 \mathrm{~kg} / \mathrm{m}^{3}$. Verificou-se abatimento de $125 \mathrm{~mm}$ para o concreto sem adição de $\mathrm{NaCl}$ e $110 \mathrm{~mm}$ para o com adição. 

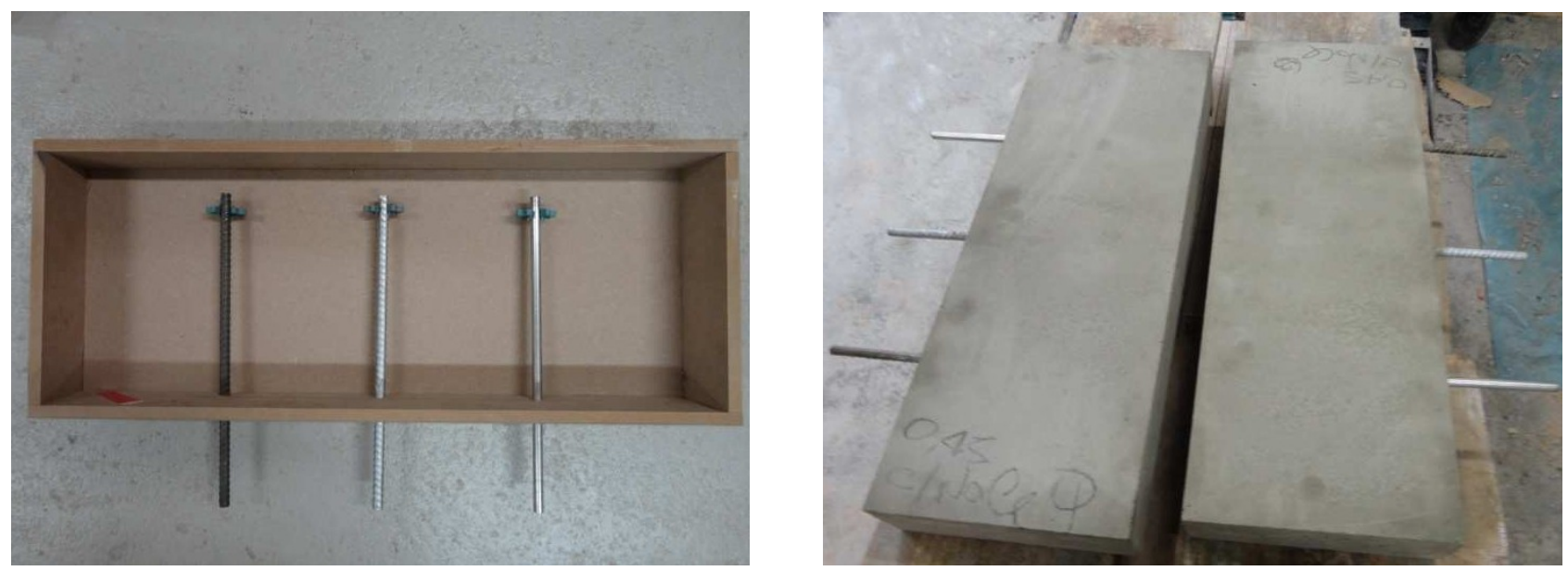

Figura 1: Vista da forma dos corpos de prova e das amostras após a concretagem.

Os ensaios eletroquímicos foram realizados com o equipamento GECOR 8, utilizando como eletrodo de referência um eletrodo de Cobre/Sulfato de Cobre saturado $(\mathrm{Cu} / \mathrm{CuSO} 4)$. A metodologia de ensaio seguiu as recomendações da ASTM C876 (2015) para o ensaio de potencial de corrosão, enquanto que os ensaios de resistividade e resistência de polarização foram realizados baseando-se na RILEM (2003) e RILEM (2004), respectivamente. Os ensaios de potencial de corrosão e resistência de polarização foram realizados sobre as armaduras, enquanto que o ensaio de resistividade foi realizado afastado das mesmas, em zona onde havia somente concreto, de forma à evitar a alteração do resultado pela presença do aço.

\section{RESULTADOS E DISCUSSÃO}

\subsection{Potencial de corrosão}

A Figura 2 apresenta os valores obtidos para os aços CA-50 em forma de gráfico. Nota-se que para este aço, no caso do concreto possuir $\mathrm{NaCl}$, os potenciais estiveram sempre abaixo dos $-350 \mathrm{mV}$, representando $90 \%$ de probabilidade de corrosão. Já àqueles em ambiente sem adição de cloretos mantiveram seus potenciais menos eletronegativos que -200 $\mathrm{mV}$, demonstrando a passivação do aço. Em relação aos potencias de aços em concretos sem cloretos, é visível a elevação do potencial ao longo do tempo, podendo ser resultado da própria cura do concreto, redução da umidade interna e fortalecimento da camada de passivação. A média dos potenciais dos aços CA-50 expostos ao concreto sem adição de $\mathrm{NaCl}$ com relação a/c 0,65 tornou-se aproximadamente $3 \mathrm{x}$ menos eletronegativo. Já aquele com relação a/c 0,45 , também sem adição, aproximadamente $4 \mathrm{x}$ menos eletronegativo.

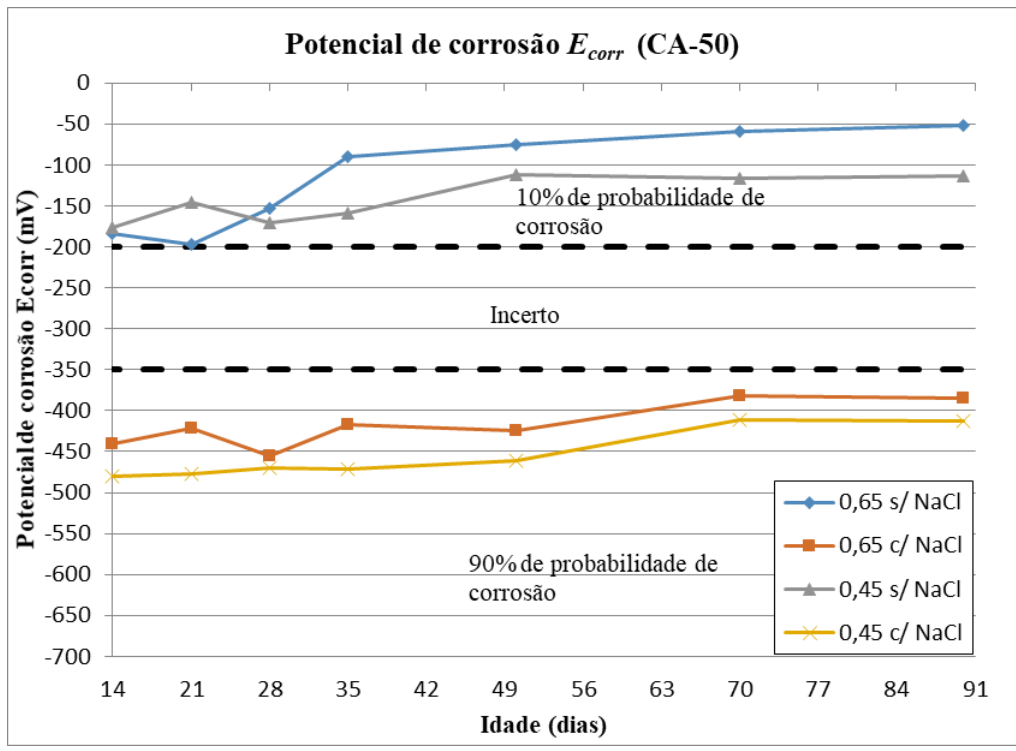

Figura 2: Média dos potenciais de corrosão para aços CA-50 
Comparando os potenciais entre concretos de água/cimento distintos, percebe-se que não há grande variabilidade. Ou seja, os potenciais são similares para exposição sem cloretos independente da relação a/c ou com cloretos. Em relação aos potenciais indicados pela RILEM (2000), percebe-se uma boa relação com os valores obtidos, estando os potenciais de concreto com cloretos entre -400 e $-600 \mathrm{mV}$ e os sem cloretos entre +100 e $-200 \mathrm{mV}$.

Os resultados obtidos para os aços CA-50 galvanizado são apresentados na Figura 3. Verifica-se que os potenciais obtidos não condizem com a correlação de probabilidade de corrosão indicadas pela ASTM C876, devido à presença da camada de galvanização. As amostras sem presença de cloretos apresentaram potenciais menos eletronegativos do que aquelas com adição do agente agressivo, porém todos em faixas mais eletronegativas do que as amostras sem a galvanização. Em relação à relação a/c, apesar da amostra de relação $0,45 \mathrm{sem} \mathrm{NaCl}$ ter o potencial menos eletronegativo, a amostra desta mesma relação apresentou menores potenciais do que a amostra de relação 0,65 . A tendência de potenciais mais eletronegativos na presença de cloretos teve o mesmo comportamento apresentado por Zheng et al (2018).

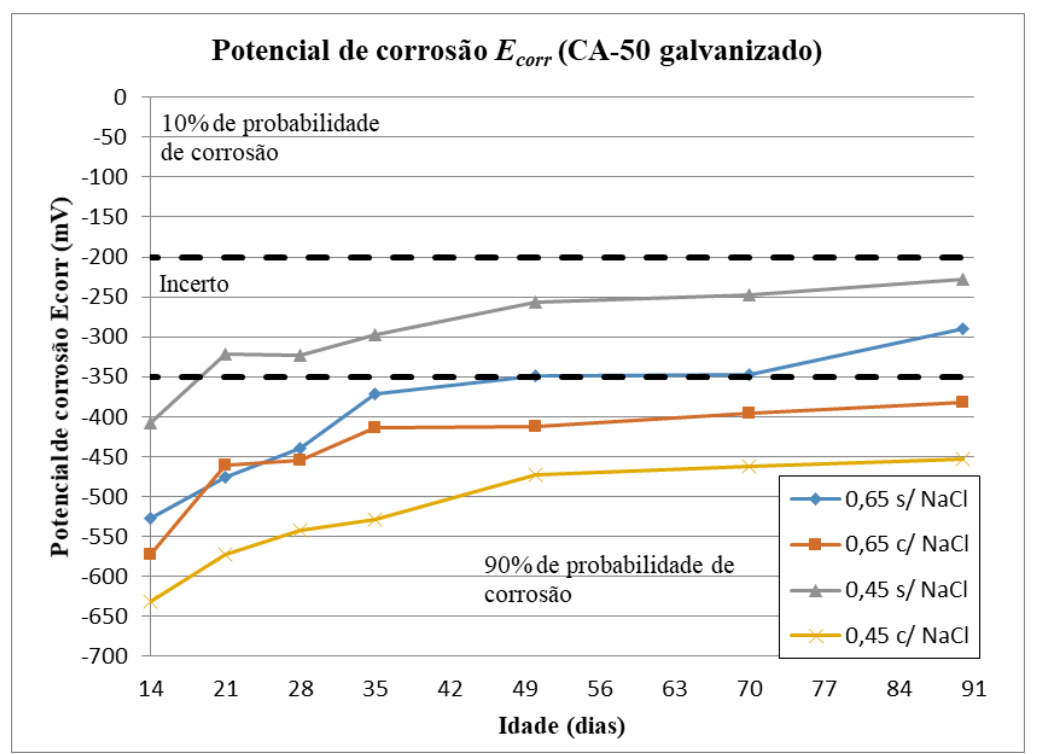

Figura 3: Média dos potenciais de corrosão para os aços CA-50 galvanizados

Percebe-se que os aços expostos ao $\mathrm{NaCl}$ apresentaram potenciais mais eletronegativos do que aqueles em ambiente normal. Apesar de até os 35 dias os aços expostos ao concreto com relação a/c 0,65 sem cloretos ainda estarem com potencial na faixa abaixo de $-350 \mathrm{mV}$, nas demais idades, bem como no concreto com a/c 0,45 sem adição de $\mathrm{NaCl}$, os potenciais estiveram na faixa entre $-200 \mathrm{mV}$ e $-350 \mathrm{mV}$. Ressalta-se, contudo, que a os valores da RILEM (2000) são para os aços CA-50 e inoxidáveis, sendo seu uso adaptado ao galvanizado, tendo em vista o comportamento apresentado.

A média dos potenciais de corrosão observados para os aços inoxidáveis ao longo das idades de ensaio são apresentados na Figura 4. Seguindo a tendência esperada, os aços com adição de $\mathrm{NaCl}$ apresentaram potenciais mais eletronegativos do que aqueles sem. $\mathrm{O}$ aço inoxidável apresentou potencial se enquadrando em $10 \%$ de probabilidade de corrosão quando exposto à concretos sem adição de $\mathrm{NaCl}$ e posicionou-se no intervalo entre -200 e $-350 \mathrm{mV}$ quando com cloreto, resultando em incerteza quanto à ocorrência ou não de corrosão. 


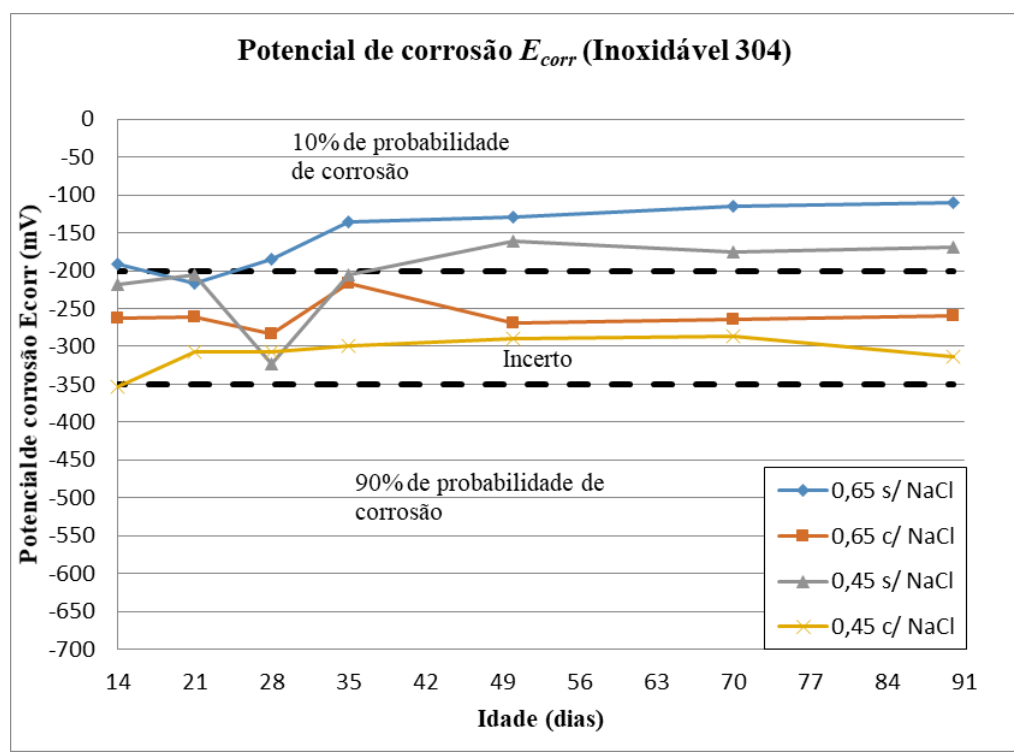

Figura 4: Média dos potenciais de corrosão para os aços inoxidáveis austeníticos

Os potenciais apresentaram variabilidade acentuada nas primeiras idades, com a posterior estabilização nas idades de 50, 70 e 90 dias. Através da análise do Ecorr, nota-se que o ambiente mais agressivo influenciou nos potenciais apresentados. Contudo, sua real determinação necessita de ensaios complementares para determinação da real situação da armadura. A adição de $3 \%$ de $\mathrm{NaCl}$ em relação à massa de cimento não foi suficiente para provocar potenciais mais eletronegativos que $-350 \mathrm{mV}$, como o ocorrido com o aço CA-50, sendo isso indicativo de uma maior resistência à corrosão.

Em relação aos potenciais indicados pela RILEM (2003), percebe-se uma boa relação com os valores obtidos para o aço CA-50 sem galvanização, estando os potenciais de concreto com cloretos entre $-400 \mathrm{mV}$ e $-600 \mathrm{mV}$ e os sem cloretos entre $-50 \mathrm{mV}$ e $-200 \mathrm{mV}$. Avalia-se que a pouca variabilidade apresentada nos resultados é fruto do ambiente de exposição ser interno e controlado, sem a presença de intempéries, que poderiam afetar os resultados. A não ocorrência de carbonatação também auxilia, evitando uma resistividade elevada no cobrimento, que venha a afetar as leituras. As amostras inoxidáveis também apresentaram valores condizentes com os especificados, principalmente na situação sem cloretos.

\subsection{Resistividade do concreto}

A Figura 5 apresenta um comparativo entre os potenciais de corrosão dos aços com as resistividades do concreto. Notase o comportamento diferenciado entre os aços CA-50, CA-50 galvanizado e Inoxidável 304. Com exceção da medição aos 35 dias do concreto com relação a/c 0,45 sem adição de $\mathrm{NaCl}$ e da de 90 dias de relação a/c 0,45 com adição de $\mathrm{NaCl}$, nota-se que a resistividade aumentou ao longo do tempo. Esta tendência está de acordo com o apresentado por Andrade et al. (2013) onde nota-se o aumento da resistividade ao longo de 200 dias. 


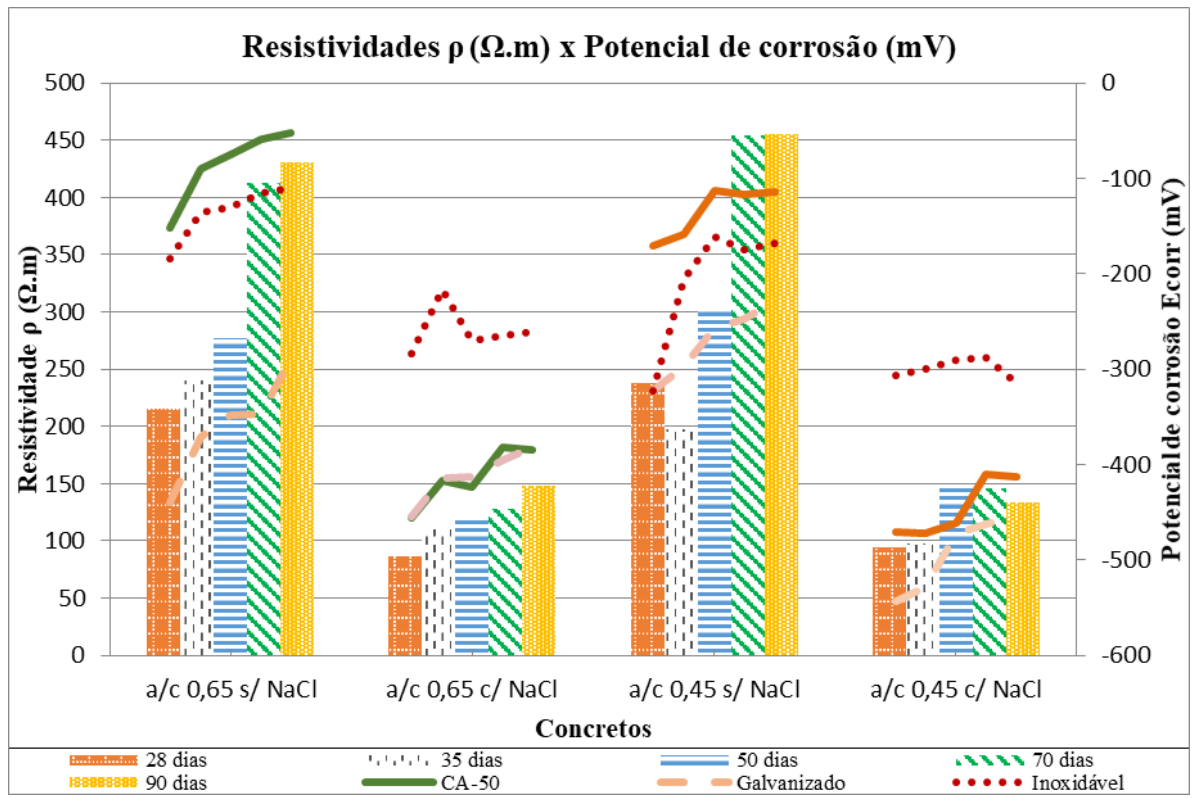

Figura 5: Evolução e comparação entre resistividades e potenciais de corrosão

Os concretos com adição de $\mathrm{NaCl}$ apresentaram resistividades inferiores àqueles sem adição pela maior retenção de água pelos íons cloreto. Nos concretos sem adição de $\mathrm{NaCl}$, com exceção da idade de 35 dias, a resistividade dos concretos com relação a/c 0,45 sempre foi superior ao de a/c 0,65. Isso ocorre pelo fato da resistividade ser consequência dos vazios e da quantidade de solução presente nos poros, fatores estes afetados diretamente pela relação $\mathrm{a} / \mathrm{c}$.

A análise de resultados proposta por Broomfield (2006), demonstra uma melhor relação com os resultados obtidos. Todos os valores entre 100 e $500 \Omega$.m, valores estes abrangendo a totalidade dos resultados com exceção daqueles com adição de $\mathrm{NaCl}$ antes dos 35 dias em idades novas, são considerados como indicadores de "Taxa de corrosão moderada à alta onde o aço está despassivado". No caso de resistividades inferiores à $100 \Omega$.m, a resistividade não seria o fator controlador da taxa de corrosão.

Quando comparados com os valores de referência apresentados pela RILEM (2003), os valores obtidos para os concretos sem adição de $\mathrm{NaCl}$ enquadram-se com os de referência para ambientes externos em cimentos sem adições (100 - $400 \Omega . \mathrm{m})$ até os 72 dias, ultrapassando este limite após esta idade. Esta resistividade mais elevada pode ser ocasionada pela pouca idade das amostras.

No caso dos aços CA-50, fica clara que a presença de $\mathrm{NaCl}$ teve como consequências tanto a queda da resistividade quanto na média dos potenciais de corrosão. O aço CA-50 galvanizado apresentou a mesma tendência de potencial com menor gradiente. Já o aço inoxidável 304 apresentou comportamento similar em todos os casos, independentemente da resistividade.

Percebe-se que com os teores de adição de $\mathrm{NaCl}$ utilizados, no aço CA-50 é possível realizar uma análise qualitativa do risco da estrutura avaliando os valores de potencial de corrosão e resistividade conjuntamente. É possível visualizar a probabilidade de corrosão associada aos potenciais abaixo de $-350 \mathrm{mV}$ nos concretos com resistividade menor e potenciais de corrosão indicativos de passivação (acima de $-200 \mathrm{mV}$ ) no caso de resistividades elevadas.

Para o aço CA-50 galvanizado, apesar da maioria das médias dos potenciais serem mais eletronegativo que $-350 \mathrm{mV}$, percebe-se que no caso de resistividades menores, obteve-se potenciais menores, estando os potenciais na zona de corrosão incerta ou $90 \%$ de probabilidade de corrosão. Já para o aço inoxidável, a queda na resistividade dos concretos não refletiu em queda no Ecorr dos aços. Ou seja, em análise conjunta dos potenciais e resistividade, o aço inoxidável apesar de estar em um local mais propício à corrosão, continua passivado. 


\subsection{Densidades de Corrente}

A adição de $\mathrm{NaCl}$ provocou a despassivação dos CA-50, manteve os aços galvanizados oscilando entre passivação e corrosão ativa e não provocaram alterações no aço inoxidável austenítico $304 \mathrm{em}$ ambos os concretos. A Figura 6 apresenta a média dos valores de densidade de corrente obtidos para os aços CA-50. Enquanto os valores de Icorr obtidos para os aços expostos aos concretos sem $\mathrm{NaCl}$ mantiveram-se constantemente passivados, os aços expostos à cloretos tiveram seus valores variando entre corrosão alta e corrosão baixa durante os ensaios, sempre, contudo, estando com densidades de corrente acima do convencionado como "passivação".

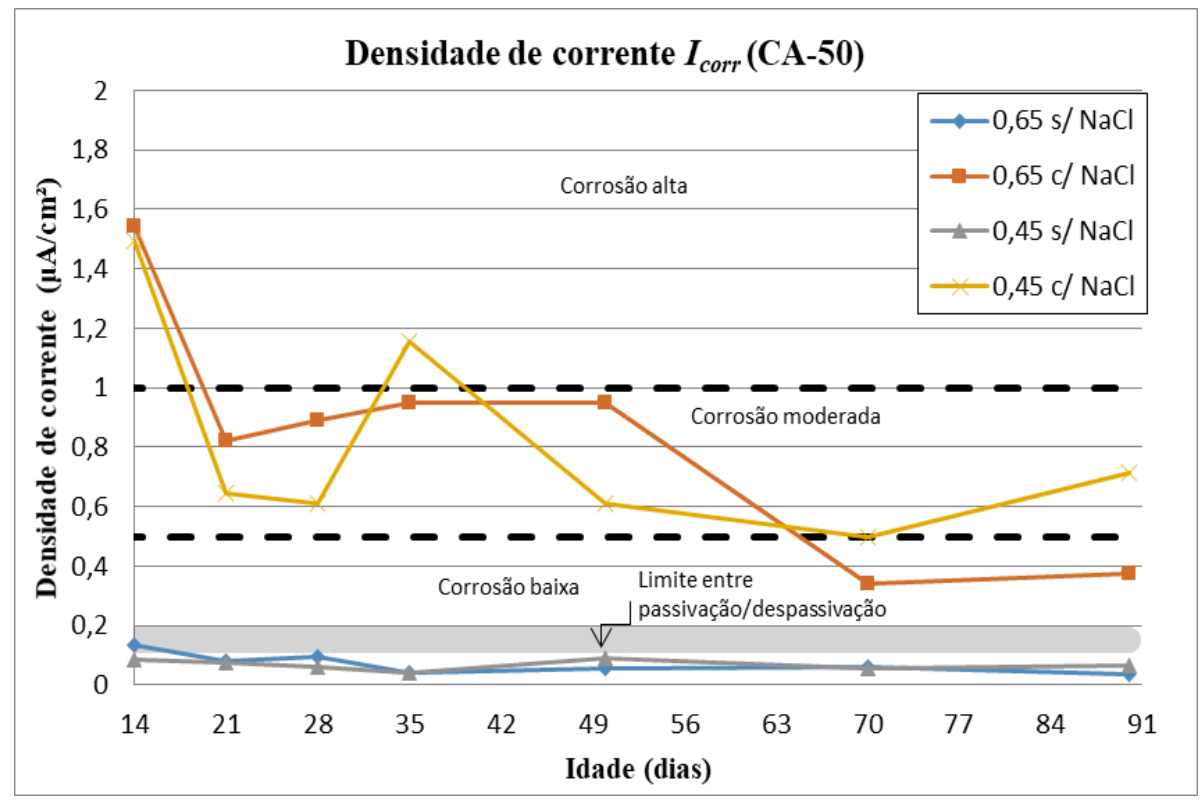

Figura 6: Densidades de corrente para aços CA-50

Como esperado, sem a perturbação gerada pelos cloretos, os aços expostos ao concreto convencional, independente da relação a/c utilizada, mantiveram-se passivados, com densidades de corrente abaixo de $<0,1 \mu \mathrm{A} / \mathrm{cm}^{2}$. No caso dos aços expostos ao $\mathrm{NaCl}$, percebe-se que as densidades de corrente sempre foram indicativas de corrosão. Pelo fato do $\mathrm{NaCl}$ ter sido adicionado já durante a concretagem das peças, não notou-se influência das relações a/c em relação às densidades de corrente instantâneas. Por vezes o concreto com maior densidade de corrente é o com a/c 0,65 , como nas idades de 14, 21 e 50 dias. Por outras, há maiores densidades instantâneas nos com água/cimento 0,45 (idades de 28,70 e 90 dias). Para o período de ensaios, nota-se que o aumento da idade, e da resistividade por consequência, provocou uma ligeira queda nas densidades de corrente observadas nos aços despassivados.

A Figura 7 apresenta os valores obtidos para os aços CA-50 galvanizados. Ao contrário dos aços CA-50 sem tratamento superficial, as densidades de corrente estiveram no limite de passivação entre passivação e despassivação, demonstrando uma maior resistência aos cloretos. Assim como no aço CA-50, os valores obtidos na idade de 14 dias foram os mais elevados, apresentando comportamento diferenciado em relação às demais idades. Nos demais períodos de ensaio, o aço galvanizado com adição de cloretos permaneceu próximo à faixa limite entre passivação e corrosão ativa $\left(0,1-0,2 \mu \mathrm{A} / \mathrm{cm}^{2}\right)$, oscilando entre passivado e com corrosão ativa. 


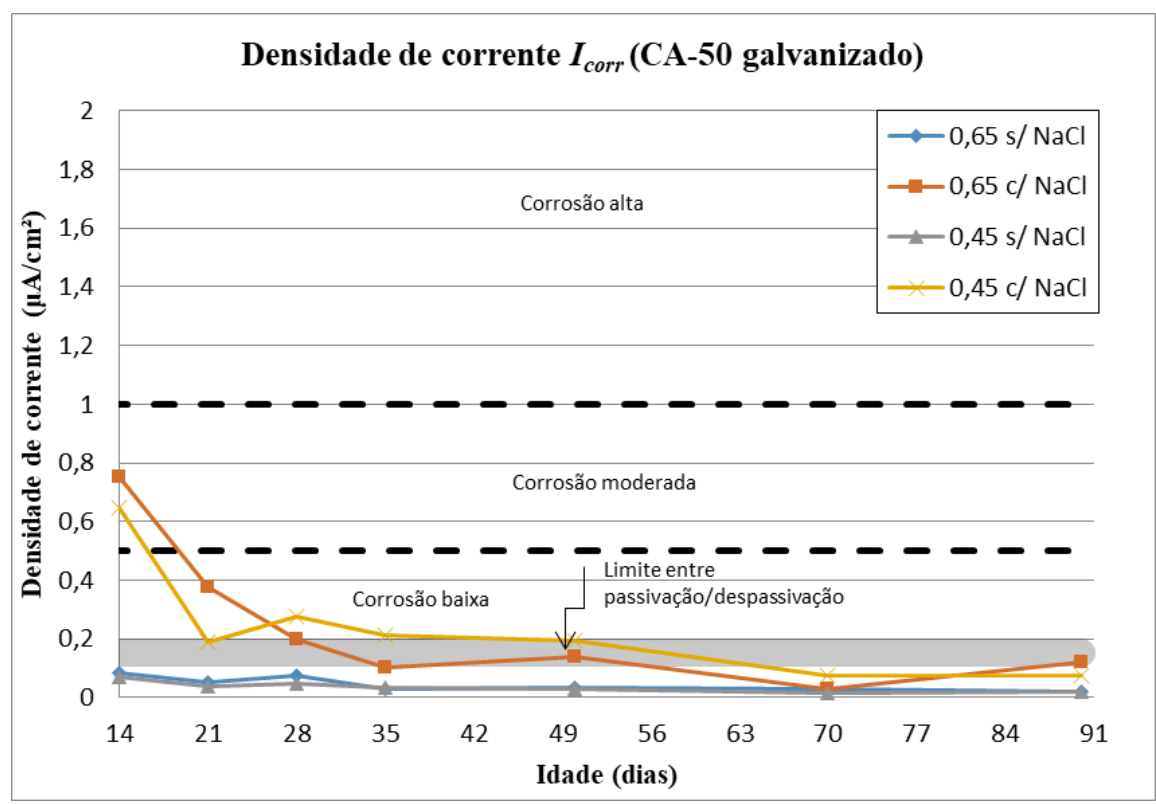

Figura 7: Densidades de corrente para aços CA-50 galvanizados

Pode-se afirmar que a utilização de $3 \%$ de $\mathrm{NaCl}$ em relação à massa de cimento está próxima do limite suportado, antes da ocorrência da despassivação, pelo aço galvanizado nas situações ensaiadas. Em relação aos aços expostos aos concretos sem adição de $\mathrm{NaCl}$, estes se mantiveram sempre passivados, com densidades de corrente abaixo de 0,1 $\mu \mathrm{A} / \mathrm{cm}^{2}$. Mesmo ambos estando passivados, o Icorr dos aços galvanizados sempre foram inferiores aos dos aços CA-50 em concretos sem adição de $\mathrm{NaCl}$, demonstrando uma passivação e qualidade superior mesmo em condições sem agentes agressivos externos.

A Figura 8 apresenta as densidades de corrente obtidos nos aços inoxidáveis 304. Nota-se que indepentemente do concreto utilizado ou da adição de $\mathrm{NaCl}$, ou não, o comportamento foi o mesmo de passivação. Ao contrário dos demais aços, o Icorr não apresentou variação alguma que caracteriza-se a influência dos cloretos no ensaio realizado. As densidades de corrente mensuradas foram praticamente constantes durante os 90 dias de ensaio, variando de 0,01 à 0,04 $\mu \mathrm{A} / \mathrm{cm}^{2}$. O comportamento apresentado pelo aço inoxidável austenítico 304, conforme avaliação pelas densidades de corrente obtidas, é muito superior aos demais aços ensaiados.

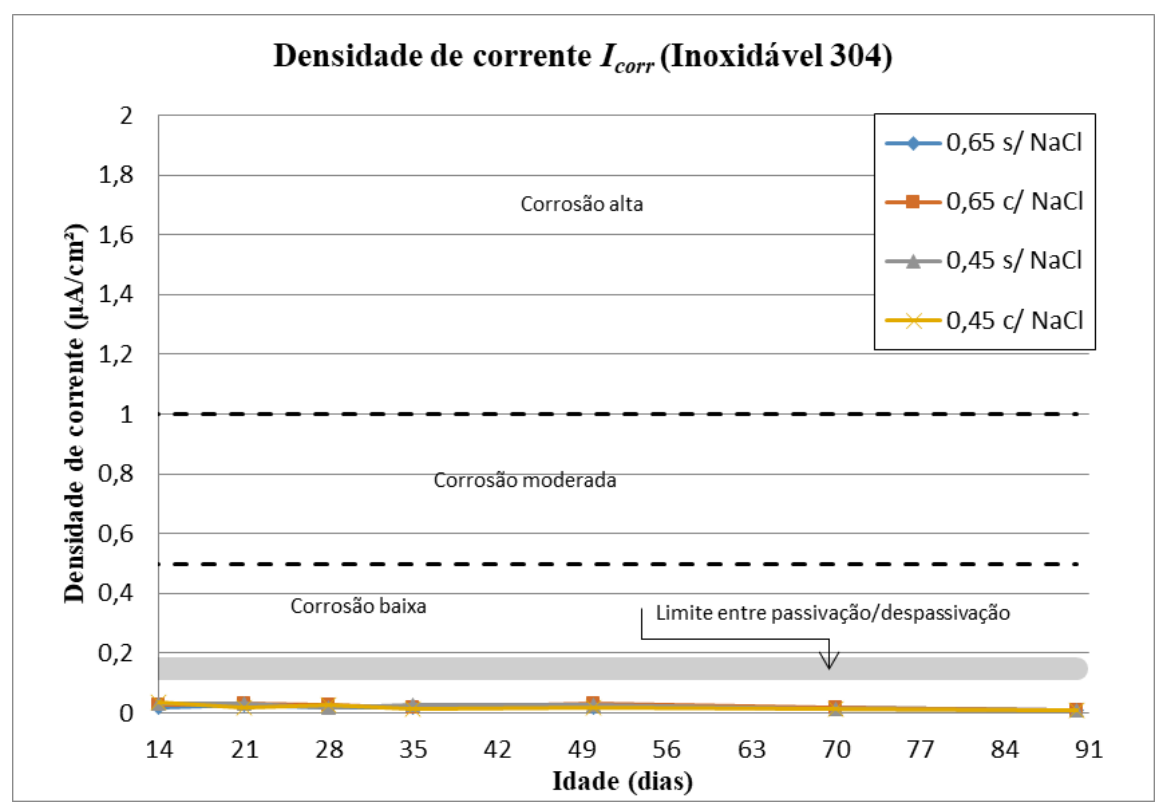

Figura 8: Densidades de corrente para os aços inoxidáveis 


\section{CONCLUSÃO}

Os potenciais de corrosão (Ecorr) obtidos durante os ensaios foram, em sua maioria, capazes de determinar os locais com corrosão ativa. Em todos os aços CA-50, bem como no caso dos aços galvanizados e inoxidáveis passivados, os valores obtidos foram conclusivos quanto à ocorrência ou não de corrosão, sendo a análise validada pelos ensaios de resistência de polarização. Pelo fato do ensaio de potencial de corrosão ser de análise termodinâmica, sem considerar a cinética da corrosão, ele pode ser não conclusivo, como ocorrido em alguns aços galvanizados e inoxidáveis no concreto com $\mathrm{NaCl}$. Desta maneira, avalia-se que sua utilização sem a presença de demais análises pode levar a resultados errôneos no caso de má interpretação dos valores obtidos.

Os valores obtidos para os aços galvanizados nos ensaios de potencial de corrosão necessitam de mais estudo em trabalhos futuros, de maneira a determinar as razões do comportamento diferenciado em relação ao documento na bibliografia disponível. Entretanto, o comportamento apresentado permitiu uma avaliação nos parâmetros utilizados para os aços de baixo carbono CA-50 e inoxidável austenítico 304.

No caso dos ensaios de resistividade, através da análise e comparação dos resultados dos concretos com e sem adição de cloretos, é possível determinar o mais suscetível à apresentar corrosão na armadura. Os concretos com presença de $\mathrm{NaCl}$ apresentaram resistividades inferiores às daqueles sem cloretos. Tendo em vista que este ensaio analisa apenas o concreto, torna-se necessária a sua combinação com outros ensaios para que seja possível determinar se o aço está com corrosão, ou apenas em um ambiente mais propício à ocorrência desta. Este conjunto de análises é ainda mais importante no caso de aços diferentes do CA-50 usual, pelo fato destes apresentarem resistências diferentes aos agentes agressivos, como verificado com os aços galvanizados e inoxidáveis.

A respeito dos ensaios de resistência de polarização, os resultados foram os mais indicativos da real situação da armadura. As densidades de corrente obtidas, permitiram a localização de corrosão moderada uniforme antes mesmo da formação de fissuras ou da presença de manchas dos produtos de corrosão na superfície do concreto.

Sobre a relação entre os ensaios quantitativos e qualitativos, o ensaio de potencial de corrosão demonstrou-se válido para localizar pontos com maior probabilidade de ocorrência do fenômeno. Contudo, não é possível através dele determinar a severidade da manifestação patológica. Apesar de haver uma faixa de valores de Ecorr onde os resultados são "incertos" quanto à ocorrência de corrosão, a técnica é válida, principalmente por haverem outras maneiras de avaliação, como através dos mapas de gradiente.

\section{AGRADECIMENTOS}

Os autores agradecem ao Laboratórios de Materiais de Construção (LMC) da Universidade do Vale do Rio dos Sinos (UNISINOS) e ao Laboratório de Ensaios e Modelos Estruturais (LEME) da Universidade Federal do Rio Grande do Sul (UFRGS) pela infraestrutura e pelos equipamentos disponibilizados para a realização dos ensaios necessários para a realização deste trabalho.

\section{REFERÊNCIAS}

ALONSO, C.; ANDRADE C.; RODRIGUEZ, J.; DIEZ, J. M. Factors controlling cracking of concrete affected by reinforcement corrosion. Materials and Structures 31, 1998, p. 435-441.

ANDRADE, C.; REBOLLEDO, N.; CASTILlO, A.; TAVARES, F.; PÉREZ, R.; BAZ, M. Evaluación de mezclas de hormigón para el nuevo canal de Panamá mediante la medida de la resistividad y de la resistência a la difusion de cloruros.. XII Congreso Latinoamericano de Patologia de la Construcción y XIV Congreso de Control de Calidad em la Construcción CONPAT, 2013, p. 57-71.

ASSOCIAÇÃO BRASILEIRA DE NORMAS TÉCNICAS (ABNT). NBR 6118 - Projeto de estruturas de concreto Procedimento. Rio de Janeiro, 2014.

ASTM Idavinternational. ASTM C876: Standard Test Method for Corrosion Potentials of Uncoated Reinforcing Steel in Concrete. EUA, 2015. 
BROOMFIELD, J. P. Corrosion of Steel in Concrete: Understanding, investigation and repair. 2nd ed. Londres, Inglaterra: E \& FN Spon, 2006.

BROOMFIELD, J. P.. The application of electrochemical and other techniques to our aging built infrastructure for the repair and conservation of buildings, bridges and structures of historic architecture and architectural importance. In: International Corrosion Congress, 2008, Las Vegas, EUA. Disponível em: $<$ http://www.jpbroomfield.co.uk/docs/20081016JPBICCpapertoTGP.pdf $>$. Acesso em: 20 set. 2013.

CARINO, N. J. Nondestructive Techniques to Investigate Corrosion Status in Concrete Structures. Journal of Performance of Constructed Facilities. v. 13, n. 3, p. 96-106, 1999

CASCUDO, O. O controle da corrosão de armaduras em concreto: Inspeção e técnicas eletroquímicas. Goiânia: UFG; São Paulo: PINI, 1997.

DAVIS, J. R. Corrosion: Understanding the Basics. EUA: ASM International, 2000.

ELSENER, B. Corrosion rate of steel in concrete - Measurements beyond the Tafel law. Corrosion Science 47, 2005, p. 3019-3033.

FIGUEIREDO, E. P.; ARAÚJO NETO, G. N.; ALMEIDA, P. A. O. Monitoração de Estruturas de Concreto. In: ISAIA, G. C. (ed.) Concreto: Ciência e Tecnologia. São Paulo: IBRACON, 2011, v. 2, p.1233-1282.

GONZÁLEZ, J. A.; MIRANDA, J. M.; FELIU, S. Considerations on reproducibility of potential and corrosion rate measurements in reinforced concrete. Corrosion Science 46, 2004, p. 2467-2485.

HANSSON, C. M. Comments on electrochemical measurements of the rate of corrosion of steel in concrete. Cement and Concrete Research 14, 1984, p. 574-584

KULAKOWSKI, M. V. Contribuição ao estudo da carbonatação em concretos e argamassas compostos com adição de sílica. 2002. 199 f. Tese (Doutorado em Engenharia Civil) - Universidade Federal do Rio Grande do Sul, Porto Alegre, 2002.

LIU, G.; ZHANG, Y.; HUANG, R. Corrosion behaviour of steel submittedto chloride and sulphate ions in simulated concrete pore solution. Construction and Building Materials, v. 115, p. 1-5, 2016.

MEHTA, P. K.; MONTEIRO, P. J. M. Concreto: Microestrutura, Propriedades e Materiais. São Paulo: IBRACON, 2014.

MICHEL, A.; OTIENO, H.; STANG, H., GEIKER, M.R. Propagation of steel corrosion concrete: Experimental and numerical investigations. Cement and Concrete Composites, v. 70, p. 171-182, 2016.

PANNONI, F. B. Princípios da proteção de estruturas metálicas em situação de corrosão e incêndio. [S.1.]: GERDAU, 2007.

RILEM TC 154-EMC. Recommendations: Half-cell potential measurements - Potential mapping on reinforced concrete structures. Materials and Structures 36, p. 461-471, 2003

RILEM TC 154-EMC. Recommendations: Test methods for on site measurement of resistivity of concrete. Materials and Structures 33, 2000, p. 603-611.

RILEM TC 154-EMC. Recommendations: Test methods for on-site corrosion rate measurement of steel reinforcement in concrete by means of the polarization resistance method. Materials and Structures 37, p. 623-643, 2004.

ZHENG, H.; DAI, J.; LI, W.; POON, C.S. Influence of chloride ion on depassivation of passive film on galvanized steel bars in concrete pore solution. Construction and Building Materials 166, p. 572-580, 2018. 